\title{
COMPARATIVE STUDY OF CONTINUOUS VERSUS INTERMITTENT SUBGLOTTIC SUCTION DRAINAGE TO PREVENT VENTILATOR ASSOCIATED PNEUMONIA IN INTUBATED PATIENTS
}

\author{
Akriti Bajracharya $^{1^{*}}$, Lalit Kumar Rajbanshi ${ }^{2}$
}

\section{Affiliation}

1. Lecturer, Department of Anaesthesiology \& Critical Care, Birat Medical College and Teaching Hospital, Nepal.

2. Associate Professor, Department of Anaesthesiology \& Critical Care, Birat Medical College and Teaching Hospital, Nepal

\section{ARTICLE INFO}

Received : 18 September, 2021

Accepted : 08 January, 2022

Published : 21 February, 2022

(C) Authors retain copyright and grant the journal right of first publication with the work simultaneously licensed under Creative Commons Attribution License CC - BY 4.0 that allows others to share the work with an acknowledgment of the work's authorship and initial publication in this journal.

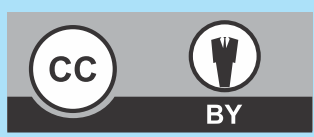

ORA 280

DOI: https://doi.org/10.3126/bjhs.v6i3.43205

* Corresponding Author

Dr. Akriti Bajracharya Lecturer

Department of Anaesthesiology \& Critical Care Birat Medical College and Teaching Hospital, Biratnagar Email:akriti854@gmail.com

ORCID: https://orcid.org/0000-0001-5948-161X

\section{Citation}

Comparative Study Of Continuous Versus Intermittent Subglottic Suction Drainage To Prevent Ventilator Associated Pneumonia In Intubated Patients. Akriti Bajracharya, Lalit Kumar Rajbanshi. BJHS 2021;6(3)16.1621-1625.

\section{ABSTRACT}

\section{Introduction}

Subglottic secretion drainage reduces the incidence of ventilator associated pneumonia (VAP). The efficacy of Continuous subglottic secretion drainage (CSSD) over Intermittent subglottic secretion drainage (ISSD) for prevention of VAP is unknown.

\section{Objectives}

Compare the efficacy of CSSD and ISSD in terms of incidence of VAP, mortality, duration of mechanical ventilation, length of ICU stay and incidence of reintubation.

\section{Methodology}

This was a prospective comparative study conducted at Birat Medical College and Teaching Hospital. A total number of 80 intubated patients for at least 48 hours duration were included. Continuous and intermittent endotracheal suctioning techniques were compared for prevention of VAP and secondary outcomes in terms of length of mechanical ventilation, length of ICU stay, multiorgan failure, reintubation and mortality rate.

Result

The incidence of VAP was $15 \%$ and $22.5 \%$ in CSSD group while it was $17.5 \%$ and $27.5 \%$ in ISSD group in first 48 hours and 96 hours of mechanical ventilation respectively.The length of mechanical ventilation was significantly less in continuous group ( $4.78 \pm 2.50$ days) than in intermittent group ( $7.18 \pm 2.09$ days) with $p$ value of 0.023 . The patients with CSSD had significantly shorter ICU stay $(5.49 \pm 3.16$ days) as compared to the patients with ISSD $(8.46 \pm 2.06$ days). The incidence of reintubation was significantly higher in intermittent group patients ( $p$ value 0.024 ). Patients in both the group had comparable incidence of multiorgan failure, spontaneous breathing trial and mortality rate.

\section{Conclusion}

The incidences of VAP and mortality were comparable in CSSD and ISSD. However CSSD significantly decreased the duration of mechanical ventilation, length of ICU stay and incidence of reintubation.

\section{KEYWORDS}

Continuous subglottic secretion drainage, intermittent subglottic secretion drainage, suction, ventilator associated pneumonia 


\section{INTRODUCTION}

Ventilator associated pneumonia is one of the common consequences of mechanical ventilation in critically ill patients in intensive care unit. It is a nosocomial infection which occurs after 48 hours of endotracheal intubation. It can occur as early as first 96 hours of mechanical ventilation. Early onset VAP is usually caused by community acquired bacteria like Hemophilus and Streptococcus. VAP which occurs more than 96 hours after mechanical ventilation is more common due to multidrug resistant microorganisms. ${ }^{1}$ The overall rate of VAP is 13.6 per 1000 ventilator days according to International Nosocomial Infection Control Consortium. ${ }^{2}$ The incidence of VAP ranges between 9 - 27\% in ICU despite wide use of preventive measures and the crude mortality rate ranges from $25 \%-50 \%{ }^{3,4-6}$ VAP also increases health care costs by increasing stay in ICU. ${ }^{2,7,8}$

The presence of endotracheal tube or tracheostomy tube interferes with normal anatomy and physiology of respiratory tract. ${ }^{3}$ Impairment of voluntary clearance of secretions in intubated patients causes macroaspiration and microaspiration. Aspiration of oropharyngeal pathogens and leakage of subglottic secretions containing bacteria around the endotracheal tube cuffs lead to entry of bacteria into lower respiratory. ${ }^{2}$ Microbial invasion of the normally sterile lower respiratory tract and lung parenchyma causes VAP. Studies show that secretions accumulate in subglottic area above cuff of endotracheal tube before reaching lower respiratory tract. ${ }^{9}$

An endotracheal tube with specially designed dorsal lumen that opens immediately above the cuff is used for subglottic secretion drainage (SSD). Previous meta analyses have shown that SSD decreased the rate of occurrence of VAP. ${ }^{10-12}$ Therefore, the use of SSD has been included in one of the components of VAP prevention bundles. In contrary, three other single center trials did not show decrease in the rate of incidence of VAP. ${ }^{13-15}$ SSD can be done continuously or intermittently. Both CSSD and ISSD are used to prevent VAP. $^{10}$ In comparison to ISSD, CSSD is more efficient in decreasing the aspiration of subglottic secretions into the lungs. However, there is paucity of the studies comparing the efficacy of continuous subglottic suctioning over intermittent subglottic suctioning in terms of decreasing VAP.

The main aim of our study was to compare the efficacy of CSSD and ISSD in prevention of VAP. The secondary objectives of our study were to determine the outcome of patients in terms of length of mechanical ventilation, number of days of ICU stay and mortality rate.

\section{METHODOLOGY}

This is a prospective comparative study which was conducted in intensive care unit of Birat Medical College and Teaching Hospital from April to August, 2021. This study was approved by Institutional Review Committee of Birat Medical College and Teaching Hospital (IRC-PA-115/207778 and date of approval was $25^{\text {th }}$ April, 2021) and written informed consent was taken from patient party. Eighty (80) patients who were intubated either in Emergency, ICU or
Operation Theatre and were in mechanical ventilation for more than 48 hours were included in this study. All the patients were intubated with Halyard Microcuff Subglottic Suctioning Endotracheal Tube. The patients with history of smoking, cough or sputum production and fever at the time of ICU admission and patients with chronic obstructive pulmonary diseases, asthma, respiratory failure and multiorgan failure were excluded from the study. The included patients were randomly divided into two groups: Continuous Subglottic Suction Drainage (CSSD) and Intermittent Subglottic Suction Drainage (ISSD). In the continuous group, subglottic suction was delivered using a standard wall suction unit at a negative pressure of $20 \mathrm{~mm}$ of $\mathrm{Hg}$. Whereas the secretions of patients in intermittent group were drained intermittently at an interval of 2 hours with the use of standard wall suction unit at a negative pressure of $100 \mathrm{~mm}$ of $\mathrm{Hg}$. Standard care of ICU was given in both groups. Every day spontaneous breathing trial was also given in every patient.

The primary outcome of this study was to compare the incidence of VAP in two suctioning technique. At 48 hours of intubation, patients were assessed for any new onset fever, any new changes in chest $X$-ray and purulent sputum production. If any one of them was present, gram stain and culture sensitivity of endotracheal tube secretions were sent. Likewise, other parameters which include Glasgow coma score (GCS), $\mathrm{PaO}_{2} / \mathrm{FiO}_{2}$ ratio, total leukocyte count, mean arterial pressure (MAP), serum bilirubin, serum platelet count and serum creatinine were also noted at the time of admission, at 48 hours and 96 hours of endotracheal intubation. All the included patients were assessed for development of VAP at 48 and 96 hours of endotracheal intubation. In the meantime, we also consider secondary outcomes like length of mechanical ventilation, length of ICU stay, duration of spontaneous breathing trials, re-intubation, mortality rate and presence of multiorgan failure.

Data was collected and entered in Microsoft Office Excel. Then data was analyzed using Statistical Software IBM SPSS statistics (version 23). The sample size of 80 was calculated on the basis of efficacy rates of continuous and intermittent SSD according to the study done by Wang $\mathrm{F}$ et al ${ }^{10}$ where the estimated efficacy rates were assumed to be $20 \%$ and $55 \%$ respectively. With an $\alpha$ error of $5 \%$ and power of study 80 , total sample size was detected to be 80 (40 in each group). Continuous data was presented as mean and standard deviation whereas categorical data was presented as frequency and percentage. Paired t test was used to compare mean for continuous data and Chi square test was used for categorical data. $\mathrm{P}$ value $<0.05$ was considered statistically significant.

\section{RESULTS}

A total of 100 patients were eligible initially in this study out of which 20 patients were excluded during the study period due to the various mentioned exclusion criteria. Table 1 shows demographic features of patients in both groups. The mean age, sex and history of smoking were comparable 
between the two groups. Statistically significant number of the patients in CSSD group were intubated in ICU as compared to ISSD group patients $(P=0.001)$ while a significant number of the patients were intubated in emergency in ISSD group. Likewise, the majority of patients are intubated electively (52.5\%) in CSSD. While most of the patients are intubated on emergency basis (57.5\%) in ISSD group.

Table 1: Demographic table
\begin{tabular}{|l|l|l|l|l|}
\hline \multirow{3}{*}{ Age } & & CSSD & ISSD & P value \\
\hline \multirow{2}{*}{ Sex } & & $37.08 \pm 18.75$ & $42.83 \pm 19.304$ & 0.971 \\
\hline Smoking & Male & $25(62.5 \%)$ & $27(67.5 \%)$ & \multirow{2}{*}{0.639} \\
\cline { 2 - 4 } & Female & $15(37.5 \%)$ & $13(32.5 \%)$ & \\
\hline $\begin{array}{l}\text { Intubation } \\
\text { Site }\end{array}$ & Emergency & $14(35 \%)$ & $20(50 \%)$ & 0.175 \\
\cline { 2 - 4 } & ICU & $23(57.5 \%)$ & $7(17.5 \%)$ & \\
\cline { 2 - 4 } & OT & $1(2.5 \%)$ & $13(32.5 \%)$ & \\
\hline \multirow{2}{*}{$\begin{array}{l}\text { Intubation } \\
\text { Type }\end{array}$} & Elective & $21(52.5 \%)$ & $17(42.5 \%)$ & \multirow{2}{*}{0.370} \\
\cline { 2 - 4 } & Emergency & $19(47.5 \%)$ & $23(57.5 \%)$ & \\
\hline
\end{tabular}

The table 2 shows clinical characteristics of patients at the time of enrollment in this study. The initial clinical features in terms of fever, $X$ ray changes, mean arterial blood pressure, total leukocyte count, bilirubin, platelet $\mathrm{PaO}_{2} /$ $\mathrm{FiO}_{2}$ were statistically comparable between the two groups patients. SOFA score of $4 \pm 2.32$ and $4.10 \pm 2.14$ in CSSD and ISSD group patients respectively showed that the severity of patients' condition was similar in both groups.

\begin{tabular}{|c|c|c|c|}
\hline & CSSD & ISSD & P value \\
\hline Fever & $2(5 \%)$ & $4(10 \%)$ & 0.561 \\
\hline X- ray Changes & $4(10 \%)$ & $5(12.5 \%)$ & 0.872 \\
\hline MAP & $76.250 \pm 19.86$ & $75.62 \pm 24.33$ & 0.394 \\
\hline TLC & $14.30 \pm 6.45$ & $13.91 \pm 7.17$ & 0.585 \\
\hline Bilirubin & $1.05 \pm 1.65$ & $0.70 \pm 0.47$ & 0.035 \\
\hline \begin{tabular}{|l} 
Platelet Counts \\
$(100,000)$
\end{tabular} & $2.51 \pm 0.72$ & $2.70 \pm 0.97$ & 0.523 \\
\hline Creatinine & $1.85 \pm 2.28$ & $1.68 \pm 1.96$ & 0.300 \\
\hline $\mathrm{PaO}_{2} / \mathrm{FiO}_{2}$ & $303.97 \pm 158.84$ & $325 \pm 206.23$ & 0.255 \\
\hline SOFA Score & $4 \pm 2.32$ & $4.10 \pm 2.14$ & 0.686 \\
\hline
\end{tabular}

Table 3 shows the incidence of VAP. Total number of patients who developed VAP was 33. In the first 48 hours, 6 patients (15\%) developed VAP in continuous group and 7 patients (17.5\%) had VAP in intermittent group. While 9 patients $(22.5 \%)$ had VAP in continuous group and 11 patients (27.5\%) developed VAP in intermittent group in next 96 hours. Although the incidence of VAP was more in intermittent group when compared with continuous group, the results were not statistically significant. Nevertheless, sputum production was significantly increased in ISSD as compared to CSSD in 48 and 96 hours ( $p$ values 0.024 and 0.039 respectively).

Table 3: VAP Table
\begin{tabular}{|l|l|l|l|l|l|l|}
\hline VAP Indices & \multicolumn{3}{|c|}{ At 48 Hours } & \multicolumn{3}{c|}{ At 96 Hours } \\
\cline { 2 - 8 } & CSSD & ISSD & P Value & CSSD & ISSD & $\begin{array}{c}\text { P } \\
\text { Value }\end{array}$ \\
\hline TLC (1000) & 12.32 & $\begin{array}{l}11.429 \\
\pm 4.07\end{array}$ & 0.080 & $\begin{array}{l}10.33 \\
\pm 3.71\end{array}$ & $\begin{array}{l}10.75 \\
\pm 3.60\end{array}$ & 0.786 \\
\hline Pa02/FiO2 & 317.06 & 298.48 & 0.751 & 318.92 & 306.5 & 0.255 \\
\pm 198.46 & \pm 102.35 & & \pm 108.79 & \pm 128.23 & \\
\hline Fever & $4(10 \%)$ & $4(10 \%)$ & 0.793 & $3(7.5 \%)$ & $2(5 \%)$ & 0.831 \\
\hline $\begin{array}{l}\text { New X-ray } \\
\text { changes }\end{array}$ & $6(15 \%)$ & $7(17.5 \%)$ & 0.728 & $4(10 \%)$ & $6(15 \%)$ & 0.638 \\
\hline $\begin{array}{l}\text { Sputum } \\
\text { Production }\end{array}$ & $2(5 \%)$ & $10(25 \%)$ & 0.024 & $3(7.5 \%)$ & $10(25 \%)$ & 0.039 \\
\hline $\begin{array}{l}\text { VAP } \\
\text { Incidence }\end{array}$ & $6(15 \%)$ & $7(17.5 \%)$ & 0.728 & $9(22.5 \%)$ & $11(27.5 \%)$ & 0.068 \\
\hline
\end{tabular}

Table 4 shows outcomes of the patients in two groups. The length of mechanical ventilation was less in continuous group ( $4.78 \pm 2.50$ days) as compared to intermittent group (7.18 \pm 2.09 days) with $p$ value of 0.023 which is statistically significant. Similarly, the length of ICU stay was less in continuous group $(5.49 \pm 3.16$ days $)$ than in intermittent group (8.46 \pm 2.06 days) with statistically significant difference ( $p$ value 0.014 ). Patients in both the groups developed comparable multiorgan failure and spontaneous breathing trial was successful in comparable number of the patients. The patients in ISSD had significantly increased number of incidence of reintubation $(P=0.024)$. However, CSSD offered no mortality benefit over ISSD.

Table 4: Outcome Variables
\begin{tabular}{|l|l|l|c|}
\hline & \multicolumn{1}{|c|}{ CSSD } & \multicolumn{1}{|c|}{ ISSD } & P Value \\
\hline $\begin{array}{l}\text { Duration of Mechanical } \\
\text { Ventilation (days) }\end{array}$ & $4.78 \pm 2.50$ & $7.18 \pm 2.09$ & 0.023 \\
\hline ICU Stay (days) & $5.49 \pm 3.16$ & $8.46 \pm 2.06$ & 0.014 \\
\hline MultiOrgan Failure & $4(10 \%)$ & $6(15 \%)$ & 0.635 \\
\hline Spontaneous Breathing Trial & $52.26 \pm 23.61$ & $59.76 \pm 24.69$ & 0.339 \\
\hline Incidence of Reintubation & $2(5 \%)$ & $4(10 \%)$ & 0.024 \\
\hline Mortality & $3(7.5 \%)$ & $5(12.5 \%)$ & 0.271 \\
\hline
\end{tabular}

\section{DISCUSSION}

Endotracheal intubation and prolonged mechanical ventilation are the leading cause of nosocomial pneumonia and ventilator associated pneumonia which has a major impact on the morbidity and mortality of the critically ill patients. Studies showed that secretions accumulated above endotracheal cuff play an important role in developing VAP. ${ }^{3,4,16}$ Hence subglottic secretion drainage is used to remove the accumulated secretions and assumed that it might decrease the incidence of VAP. The advantage of using subglottic suction in decreasing VAP has been established by some of the studies. ${ }^{10-12}$ Both continuous and intermittent SSD have shown to reduce the development of VAP. $^{10}$

The present study showed a comparable demographic profile and clinical features at the time of admission which made the comparison of the primary and secondary objectives of the study uniform and unbiased by confounding factors. The severity of the disease in the patients in both the groups was similar. The present study looked into the incidence of ventilator associated pneumonia as a primary outcome. The incidence of VAP was $15 \%$ in continuous SSD and $17.5 \%$ in intermittent SSD at 48 hours in the study. Likewise, the incidence of VAP was $22.5 \%$ 
in continuous SSD and $27.5 \%$ in intermittent SSD at 96 hours. Relatively, the incidence of VAP was less in continuous subglottic suctioning technique though the difference was not statistically significant ( $p$ value 0.728 at 48 hours and $p$ value 0.068 at 96 hours). We assumed that the continuous suctioning of the tracheal secretion led to effective clearance of the subglottic secretions thus decreasing the probability of developing VAP. Similar findings were observed in a study conducted by Fujimoto et $\mathrm{al}^{17}$ in which the incidence of VAP was $26.7 \%$ in continuous SSD and $43.8 \%$ in intermittent SSD. Although the study showed decreased incidence of VAP in continuous group than in intermittent group, it was not statistically significant ( $p$ value 0.320 ) and the author assumed that the reason behind the cause was due to early extubation leading to exclusion of the participants from the study. The study by Fujimoto et al had higher VAP incidence in both the group as compared to our study. The reason behind it was assumed to be broad diagnostic criteria. Over the years, the diagnostic criteria for VAP has been more precise. Hence, the incidence of VAP is reduced in both groups at 48 hours and 96 hours in our study.

An overview of systemic reviews and an updated metaanalysis showed that subglottic secretion drainage (SSD) significantly reduced the incidence of VAP. ${ }^{18}$ Similarly, a review article ${ }^{19}$ showed that SSD primarily decreases the incidence of early-onset VAP. It also showed that SSD had no effect on late-onset VAP. It stated that none of the published studies were experimentally designed to demonstrate, in intention to treat, any effect on late-onset VAP. Among 20 $\mathrm{RCTs}^{20}$, four high quality studies were associated with reduction in incidence of VAP. Overall, it showed relative risk of 0.55 for the incidence of VAP in SSD versus non SSD. Likewise in a meta-analysis ${ }^{21}$, SSD reduced VAP rate by nearly half as compared to ET without SSD. Another metaanalysis ${ }^{22}$ demonstrated that SSD reduced incidence of VAP by $50 \%$.

In a multicenter trial $^{23}$, the intermittent SSD significantly reduced the incidence of early onset and late onset VAP. It also showed that 11 cases of VAP could be avoided in every 100 patients treated with SSD. In previous studies, continuous SSD also showed decreased incidence of VAP. $^{13,15,24}$ In contrary to our study, a metaanalysis ${ }^{25}$ showed no advantage of CSSD over ISSD in the incidence of VAP. The differences in methodology, end points and the included study groups were assumed to be the potential causes for not being able to find the difference between the two different types of SSD.

In our study, the patients with continuous drainage had shorter duration of mechanical ventilation and ICU stay as well, as compared to patients with intermittent drainage technique. Though statistically not significant, the incidence of VAP was relatively less in patients with continuous drainage and it was obvious that continuous drainage cleared the subglottic secretions more effectively which might have led to less number of days in mechanical ventilation and decreased length of ICU stay. This finding in our study has been supported by Fujimoto Hiroka et al. ${ }^{17}$ They demonstrated a significant decrease in duration of mechanical ventilation and length of ICU stay with the use of continuous drainage system. ${ }^{17}$ In contrary to our study, there was no advantage of CSSD over ISSD in terms of duration of mechanical ventilation, ICU stay and mortality rate in a meta-analysis. ${ }^{25}$ The continuous drainage of the subglottic secretion had led to significant decrease in the incidence of reintubation. The incidence of reintubation in CSSD is less as compared to ISSD in our study.

In our study, there is no mortality benefit of continuous drainage over intermittent drainage technique. The mortality of critically ill patients is affected by numerous clinical and pathophysiological conditions like severity of the diseases, multiorgan failure, organ support system. VAP is one of the attributable clinical condition for the mortality of critically ill patients. As there is no benefit decreasing the incidence of VAP in the present study, the mortality benefit remained comparable between the two groups. Similar to our study, Fujimoto Hiroka et al also failed to show mortality benefit of continuous drainage over intermittent drainage system. ${ }^{17}$ Mao Z et al showed that there is an association of SSD and decrease in duration of mechanical ventilation. But it failed to show a correlation between SSD and decrease in ICU stay, mortality and reintubation..$^{20}$ Whereas, a significant difference was seen in mortality when compared with SSD versus non SSD intervention in a study. ${ }^{18}$ But it did not show any association between SSD technique and decrease in length of ICU stay and duration of mechanical ventilation. A multicenter trial also showed no difference in duration of mechanical ventilation, length of ICU stay and mortality rate between continuous and intermittent drainage. ${ }^{23}$

\section{CONCLUSION}

The continuous drainage of subglottic secretions has no added benefit over intermittent drainage system in terms of decreasing the incidence of ventilator induced pneumonia and mortality. However, the use of continuous subglottic suction in clearing the secretion significantly reduced the duration of mechanical ventilation and length of ICU stay.

\section{LIMITATIONS}

This study has several limitations. First, the sample size was less in our study. Hence, significant difference in incidence of VAP could not be found between CSSD and ISSD. We found significant differences in terms of secondary outcomes only. Second, there is heterogeneity in terms of site of intubation between two groups. Third, SSD is an obvious clinical manipulation. Hence, it could not be blinded between doctors and nurses leading to unavoidable performance bias. 


\section{RECOMMENDATION}

SSD should be used in ICU inorder to decrease the incidence of VAP. CSSD is better than ISSD inorder to reduce length of mechanical ventilation and duration of ICU stay.

\section{CONFLICT OF INTEREST}

None

\section{ACKNOWLEDGEMENT}

We would like to thank all the doctors and nurses involved in this study.

\section{REFERENCES}

1. Hunter JD. Ventilator associated pneumonia. Postgrad Med. J 2006;82:172-8 doi: 10.1136/pgmj.2005.036905

2. Charles MP, Kali A, Easow JM, Joseph NM, Ravishankar M, Srinivasan S, et al. Ventilator-associated pneumonia. Australas Med J. 2014;7(8):334-344 doi: 10.4066/AMJ.2014.2105

3. Guidelines for the management of adults with hospital-acquired, ventilator-associated, and healthcare-associated pneumonia. Am J Respir Crit Care Med. 2005; 171: 388-416 doi: 10.1164/rccm.200405644ST

4. Chastre J, Fagon JY. Ventilator-associated pneumonia. Am J Respir Crit Care Med. 2002; 165: 867-903 doi: 10.1164/ajrccm.165.7.2105078

5. Blot S, Koulenti D, Dimopoulos G, Martin C, Komnos A, Krueger WA, et al. Prevalence, risk factors, and mortality for ventilator-associated pneumonia in middle-aged, old, and very old critically ill patients*. Crit Care Med. 2014;42: 601-9 doi:10.1097/01.ccm.0000435665.07446.50

6. Heyland DK, Cook DJ, Griffith L, Keenan SP, Brun-Buisson C. The attributable morbidity and mortality of ventilator-associated pneumonia in the critically ill patient. The Canadian Critical Trials Group. Am J Respir Crit Care Med. 1999;159:1249-56 doi: 10.1164/ajrccm.159.49807050

7. Safdar N, Dezfulian C, Collard HR, Saint S. Clinical and economic consequences of ventilator-associated pneumonia: a systematic review. Crit Care Med. 2005;33:2184-93 doi: 10.1097/01.ccm. 0000181731.53912.d9

8. Muscedere JG, Martin CM, Heyland DK. The impact of ventilatorassociated pneumonia on the Canadian health care system. J Crit Care. 2008;23(1):5-10 doi: 10.1016/j.jcrc 2007.11.012

9. Greene R, Thompson S, Jantsch HS, Teplick R, Cullen DJ, Greene EM, et al. Detection of pooled secretions above endotracheal-tube cuffs: value of plain radiographs in sheep cadavers and patients. AJR Am J Roentgenol. 1994;163(6):1333-7 doi: 10.2214/ajr.163.6.7992723

10. Wang F, Bo L, Tang L, Lou J, Wu Y, Chen F, et al. Subglottic secretion drainage for preventing ventilator associated pneumonia: an updated meta-analysis of randomized controlled trials. J Trauma Acute Care Surg. 2012;72(5): 1276-85 doi: 10.1097/TA.0b013e318247cd33

11. Muscedere J, Rewa O, McKechnie K, Jiang X, Laporta D, Heyland DK. Subglottic secretion drainage for the prevention of ventilatorassociated pneumonia: a systematic review and meta-analysis. Crit Care Med. 2011;39(8):1985-91 doi: 10.1097/CCM.0b03e318218a4d9

12. Frost SA, Azeem A, Alexandrou E, Tam V, Murphy JK, Hunt L, et al. Subglottic secretion drainage for preventing ventilator associated pneumonia: a meta-analysis. Aust Crit Care. 2013;26(4):180-8 doi: 10.1016/j.aucc.2013.03.003

13. Bouza E, Perez MJ, Munoz P, Rincon C, Barrio JM, Hortal J. Continuous aspiration of subglottic secretions (CASS) in the prevention of ventilator-associated pneumonia in the postoperative period of major heart surgery. Chest 2008;134(5):938-46 doi: 10.1378/chest.08-0103
14. Kollef MH, Skubas NJ, Sundt TM. A randomized clinical trial of continuous aspiration of subglottic secretions in cardiac surgery patients. Chest 1999;116(5):1339-46 doi:10.1378/chest.116.5.1339

15. Valles J, Artigas A, Rello J, Bonsoms N, Fontanals D, Blanch L, et al. Continuous aspiration of subglottic secretions in preventing ventilator-associated pneumonia. Ann Intern Med 1995;122(3): 179-186 doi: 10.7326/0003-4819-122-3-199502010-00004

16. Klompas M. Does this patient have ventilator-associated pneumonia? JAMA. 2007; 297: 1583-93 doi: 10.1001/jama.297.14.1583

17. Fujimoto Hiroka, Yamaguchi Osamu, Hayami Hajime, Shimosaka Mika, Tsuboi Sayaka, Sato Mitsunori et al.Efficacy of continuous versus intermittent subglottic secretion drainage in preventing ventilatorassociated pneumonia in patients requiring mechanical ventilation. $A$ single center randomized control trial. Oncotarget 2018;9(22):1587682 doi: 10.18632 /oncotarget. 24630

18. Pozuelo-Carrascosa DP, Herraiz-Adillo A, Alvarez-Bueno C, Anon JM, Martinez-Vizcaino V,Cavero-Redondo I. Subglottic secretion drainage for preventing ventilator-associated pneumonia: an overview of systematic reviews and an updated meta-analysis. Eur Respir Rev 2020;29:190107 doi: 10.1183/16000617.0107-2019

19. Lacherade JC, Azais MA, Caroline P, Colin G. Subglottic secretion drainage for ventilator associated pneumonia prevention: an underused efficient measure. Ann Transl Med 2018;6(21):422. doi: 10.21037/atm.2018.10.40

20. Mao Z, Gao L, Wang G, Liu C, Zhao Y, Gu Wanjie, et al. Subglottic secretion suction for preventing ventilator-associated pneumonia: an updated meta-analysis and trial sequential analysis. Crit Care 2016;20:353 doi: https://doi.org/10.1186/s13054-016-1527-7

21. Wang R, Zhen X, Yang BY, Guo XZ, Zeng X, Deng CY. Subglottic secretion drainage for preventing ventilator associated pneumonia: a metaanalysis. Chinese Nursing Research 2015;2:55-60 doi: https://doi.org/ 10.1016/j.cnre.2015.03.001

22. Dezfulian C, Shojania K, Collard HR, Kim HM, Matthay MA, Saint S. Subglottic secretion drainage for preventing ventilator-associated pneumonia: a meta-analysis. AmJMed 2005;118:11-8 doi: 10.1016/j.amjmed.2004.07.051

23. Lacherade JC, Jonghe BD, Guezennec P, Debbat K, Hayon J, Monsel A, et al. Intermittent subglottic secretion drainage and ventilator associated pneumonia: a multicenter trial. Am J Respir Crit Care Med 2010;182:910-7 doi: 10.1164/rccm.200906-08380C

24. Yang CS, Qiu HB, Zhu YP, Huang YZ, Xu XT, Gao L. [Effect of continuous aspiration of subglottic secretions on the prevention of ventilatorassociated pneumonia in mechanically ventilated patients: a prospective, randomized, controlled clinical trial]. [Article in Chinese] Zhonghua Nei Ke Za Zhi. 2008;47:625-9. PMID: 19080291

25. Zunjia Wen, Haiying Zhang, Jianping Ding, Zhuo Wang, Meifen Shen. Continuous versus intermittent subglottic secretion drainage for prevention of ventilator associated pneumonia : a systemic review. Crit Care Nurse 2017;37(5):e10-e17 doi: 10.4037/ccn2017940 